\title{
FORMULATION OF ORALLY DISINTEGRATING TABLETS OF CINNARIZINE BY USING DIRECT COMPRESSION METHOD
}

\author{
RASHA KHALID DHAHIR', MYASAR Al-KOTAJI²
}

1,2Department of Pharmaceutics, College of Pharmacy, University of Mosul, Mosul, Iraq

Email: rasha_pharma83@yahoo.com

Received: 07 Sep 2018, Revised and Accepted: 19 Nov 2018

\begin{abstract}
Objective: The aim of this work was to formulate and evaluate orally disintegrating tablets of cinnarizine that were prepared by direct compression method using different types of diluents and super disintegrants. The rationale behind this work was to accelerate the disintegration of the tablet to provide rapid dissolution, quick action and enhanced bioavailability of the drug.
\end{abstract}

Methods: The tablets were prepared by direct compression method using different types of diluents as mannitol, microcrystalline cellulose (MCC), and lactose. Different super disintegrants were used such as crospovidone (CP), sodium starch glycolate (SSG) and Kyron T-314; Kyron T-314 was used in different concentrations of $5 \%, 6 \%, 7 \%$, and $8 \%$. The prepared formulae (F1-F9c) were subjected to flowability studies and postcompression evaluation studies. The optimized formula was selected depending on the time of disintegration and dissolution; then it was subjected to drug-excipient compatibility study and stability study.

Results: Flowability results were ranging from excellent, excellent to good, and good to fair according to the type of the diluent used. All of the prepared tablets showed acceptable hardness, friability, drug content, and disintegration. A rapid disintegration of $11.66 \pm 2.25 \mathrm{~s}$ with the highest percentage 2 min-drug release of $74.55 \pm 3.01 \%$ was obtained by using the diluent lactose and the super disintegrant Kyron T-314 (8\%) in the formula F9c. The infrared spectroscopic studies of the formula F9c showed no drug-excipient interaction. In addition, the stability study indicated that the optimized formula is a stable formula.

Conclusion: Formula F9c of a rapidly disintegrating tablet was easy to be manufactured, and the results showed that this formula had a rapid disintegration, high dissolution profile, no noticeable chemical incompatibility and it was stable upon storage.

Keywords: Orally disintegrating tablets, Super disintegrants, Cinnarizine, Direct compression

(C) 2019 The Authors. Published by Innovare Academic Sciences Pvt Ltd. This is an open access article under the CC BY license (http://creativecommons.org/licenses/by/4.0/) DOI: http://dx.doi.org/10.22159/ijap.2019v11i1.29599

\section{INTRODUCTION}

Over the last decade, the development of orally disintegrating tablets (ODTs) has received increased interest among pharmaceutical industries and researchers [1]. Such dosage form is not only preferable for elderly and children, but also for adults consumers who like to have their medication obtainable at any time [2].

Orodispersible tablets are defined according to European Pharmacopoeia as "uncoated tablets intended to be placed in the mouth where they disperse rapidly before being swallowed" [3]. ODTs are also known as rapid dissolve, fast melting, quick disintegrating, fast dispersing, and/or rapid melt tablets [4]. After being disintegrated in saliva, ODTs produce a solution or suspension that can be swallowed easily by the patient [5]. It means that this dosage form mixes the advantages of both liquid and solid formulations. Also, the opportunity for pregastric absorption of the drug may increases as the drug passes through the mouth, pharynx, and esophagus toward the stomach. In such case bioavailability of the drug is significantly improved when compared with that of the conventional tablets [6].

Direct compression can be regarded as the easiest, most appropriate, and simplest way to obtain a rapidly disintegrating tablet with adequate structural integrity. In the direct compression method, the most important factor to be taken in concern is the selection of suitable excipients with good disintegration properties and compatibility. Several factors should be considered in selecting the super disintegrants because these agents do not affect the rate of disintegration only, but they also affect friability, hardness and how the tablet feels in the mouth. The disintegration and dissolution properties of the direct compressible ODTs are based on the single or combined action of disintegrants and water-soluble excipients. However, the disintegrants have the major role. Choosing of a suitable disintegrant type and in optimal concentration is essential for ensuring high disintegration rate [7].
Cinnarizine is histamine $\mathrm{H}_{1}$-receptor blocker and voltage-gated calcium channel blocker used for the treatment of vertigo, Meniere's disease, motion sickness, nausea, vomiting, and other symptoms of vestibular origin [8]. The drug is tasteless and water-insoluble [9]; therefore it can be considered as a model drug to be formulated as ODTs. Pharmaceutically, it belongs to the biopharmaceutical classification system (BCS) class II, and drug dissolution is the limiting step for its absorption [10].

Preparation of cinnarizine ODTs with enhanced disintegration and dissolution rate is beneficial because diseases like motion sickness, nausea and vomiting require immediate release of the drug from the dosage form. In addition, cinnarizine ODTs may improve patient compliance and reduce the side effect of the drug. The aim of the present work was to formulate cinnarizine orally disintegrating tablets by direct compression method, to ensure that high percentage of the drug can be dissolved in the stomach within a short period of time which increases the opportunity for high bioavailability of the drug.

\section{MATERIALS AND METHODS}

\section{Materials}

Cinnarizine powder was purchased from Apollo Healthcare Resources, Singapore. Lactose, Super Tab® 40LL was provided by DFE pharma, Germany. Microcrystalline cellulose PH 102 was taken from JRS pharma, US. Pearlitol, mannitol (400) DC was purchased from Roquette Pharma, French. Kyron T-314 was obtained from COREL PHARMA CHEM, India. Crospovidone (CP), sodium starch glycolate (SSG), sodium saccharin, citric acid anhydrous, talc, and magnesium stearate were supplied from Awamedica Drug Industries, Iraq.

Preparation of cinnarizine ODTs by direct compression method using different types of super disintegrants

Twelve different formulae of orally disintegrating tablets of cinnarizine (25 mg) were prepared by direct compression method using three 
different types of diluents and three different types of super disintegrants as demonstrated in table 1 . Sodium saccharine and citric acid were added to mask any unacceptable taste while magnesium stearate and talc were added as lubricant and glidant respectively. All the ingredients were passed through a sieve (mesh \# 60) and blended thoroughly for $10 \mathrm{~min}$, except talc and magnesium stearate which were added later and blended for further 2-3 min. The powder blend was compressed in tablets using $8 \mathrm{~mm}$ normal flat punches to get tablets of $180 \mathrm{mg}$ weight using multi-rotary tablet compression machine (Mini press II MT tablet compression, Rimek, India).

Table 1: Composition of cinnarizine (25 mg) ODTs with a total weight of $180 \mathrm{mg}$

\begin{tabular}{|c|c|c|c|c|c|c|c|c|c|c|c|c|}
\hline Ingredients \% (w/w) & F1 & F2 & F3 & F4 & F5 & F6 & F7 & F8 & F9 & F9a & F9b & F9c \\
\hline Cinnarizine & 13.9 & 13.9 & 13.9 & 13.9 & 13.9 & 13.9 & 13.9 & 13.9 & 13.9 & 13.9 & 13.9 & 13.9 \\
\hline Pearlitol, mannitol (400) DC & 79.1 & 78.1 & 77.1 & - & - & - & - & - & - & - & - & - \\
\hline MCC PH 102 & - & - & - & 79.1 & 78.1 & 77.1 & - & - & - & - & - & - \\
\hline Lactose, Super Tab® 40LL & - & - & - & - & - & - & 79.1 & 78.1 & 77.1 & 76.1 & 75.1 & 74.1 \\
\hline $\mathrm{CP}$ & 3 & - & - & 3 & - & - & 3 & - & - & - & - & - \\
\hline SSG & - & 4 & - & - & 4 & - & - & 4 & - & - & - & - \\
\hline Kyron-T314 & - & - & 5 & - & - & 5 & - & - & 5 & 6 & 7 & 8 \\
\hline Sodium saccharin & 0.5 & 0.5 & 0.5 & 0.5 & 0.5 & 0.5 & 0.5 & 0.5 & 0.5 & 0.5 & 0.5 & 0.5 \\
\hline Citric acid & 0.5 & 0.5 & 0.5 & 0.5 & 0.5 & 0.5 & 0.5 & 0.5 & 0.5 & 0.5 & 0.5 & 0.5 \\
\hline Magnesium-stearate & 1 & 1 & 1 & 1 & 1 & 1 & 1 & 1 & 1 & 1 & 1 & 1 \\
\hline Talc & 2 & 2 & 2 & 2 & 2 & 2 & 2 & 2 & 2 & 2 & 2 & 2 \\
\hline Total weight $\%(w / w) 180 \mathrm{mg}$ & 100 & 100 & 100 & 100 & 100 & 100 & 100 & 100 & 100 & 100 & 100 & 100 \\
\hline
\end{tabular}

${ }^{*} \mathrm{w} / \mathrm{w}$ : Percentage by weight

\section{Flowability study of the prepared powder mixtures}

\section{Measuring of the angle of repose}

The angle of repose is a characteristic related to inter-particulate friction or resistance to movement between particles [11]. It was determined using fixed height funnel method by measuring the height of the cone and the base formed by the powder falling through a funnel. It is calculated by applying the following equation:

$$
\tan \theta^{\circ}=\frac{h}{r}
$$

Where $\theta^{\circ}=$ Angle of repose; $\mathrm{h}=$ height of powder cone; $\mathrm{r}=$ radius of powder cone.

\section{Compressibility index (Carr's Index) and Hausner's ratio}

"Compressibility is the measure obtained from the shrinkage of the apparent volume for a defined mass of powder after the rearrangement of the grains/particles during the application of tapping"[12]. Compressibility index (Carr's Index) and Hausner's ratio were determined by gently loading a certain amount of the powder through a funnel into $100 \mathrm{ml}$ cylinder, and tapped until the volume stopped changing. Carr's index and Hausner's ratio were calculated according to the equation below:

$$
\text { Carr's index }=\frac{\mathrm{V}^{\circ}-\mathrm{vf}}{\mathrm{V}^{\circ}} \times 100 \text {, Hausner' } \mathrm{s} \text { ratio }=\frac{\mathrm{V}^{\circ}}{\mathrm{Vf}}
$$

Where $\mathrm{v}^{\circ}=$ untapped apparent volume in $\mathrm{ml}, \mathrm{v}_{\mathrm{f}}=$ taped volume of blend in $\mathrm{ml}$.

\section{Evaluation of the prepared cinnarizine tablets}

\section{Hardness (Crushing strength)}

Hardness test was done to determine the resistance of a tablet to the mechanical shocks during handling, shipping, storage, and transportation [13]. It was measured by tablet breaking force testerUSP (Electrolab, India) and expressed in Newton (N).

\section{Friability (Resistance to abrasion)}

Friability test can be done to evaluate the ability of the tablets to withstand abrasion in packing, handling and transporting. Twenty tablets are randomly taken, dedusted, weighed accurately and transferred into friability tester-1 (EF-2, Electrolab, India). After 100 rotations, the tablets were dedusted and weighed again, the friability percentage was calculated for each formula by the following equation [14]:

$$
\text { Friability } \%=\frac{W(\text { initial })-W(\text { final })}{W(\text { initial })} \times 100
$$

\section{Uniformity of weight}

Twenty tablets were selected at random, and the average weight was calculated. The variation of the weight of the individual tablet from the average weight was calculated. In this work, the percentage limits allowed of weight variation according to the average weight of the tablets is $7.5 \%$ [3].

\section{Disintegration test}

Disintegration time for cinnarizine ODTs was determined by disintegration tester-3 USP, (Electrolab, India), using $900 \mathrm{ml}$ of distilled water, at $37{ }^{\circ} \mathrm{C} \pm 0.5$ [3]. The time needed for complete disintegration of the tablet with no palpable mass remaining in the apparatus was measured in seconds [15]. The disintegration time was also measured for the marketed cinnarizine conventional tablet (Stugeron® $25 \mathrm{mg}$ tablet) as a reference.

\section{Wetting time}

The wetting time was measured using a simple procedure in which five circular tissue papers of $10 \mathrm{~cm}$ in diameter were placed in a 10 $\mathrm{cm}$ circular petri dish. $10 \mathrm{ml}$ solution of a water-soluble dye $(0.02 \%$ tartrazine dye) was added. A tablet was carefully placed on the surface of the tissue paper, the time spent for water to reach the upper surface of the tablet represents the wetting time [16].

\section{Water absorption ratio}

To measure the water absorption ratio, the same procedure as that of wetting time was followed. The initial weight of the tablet before placing it in the petri dish was recorded $\left(\mathrm{W}_{\mathrm{b}}\right)$, the wetted tablet was taken and reweighed $\left(\mathrm{W}_{\mathrm{a}}\right)$. water absorption ratio (R) was determined according to the following equation [16]:

$$
\mathrm{R}=\frac{\mathrm{Wa}-\mathrm{Wb}}{\mathrm{Wb}} \times 100
$$

Where $\mathrm{R}=$ water absorption ratio; $\mathrm{W}_{\mathrm{a}}=$ weight of the tablet after absorption; $\mathrm{W}_{\mathrm{b}}=$ weight of the tablet before absorption.

\section{Dissolution test (In vitro drug release)}

Dissolution test for the prepared ODTs of cinnarizine was performed using a dissolution test apparatus II (Pharma test, PT-DT7, Germany) with a paddle stirrer. A volume of $900 \mathrm{ml}$ of $0.1 \mathrm{~N} \mathrm{HCl} \mathrm{(pH}$ 1.2) was used as a dissolution medium at a speed of $50 \mathrm{rpm}$ and a temperature of $37{ }^{\circ} \mathrm{C} \pm 0.5$. A sample of $5 \mathrm{ml}$ of the medium was withdrawn at the predetermined time interval and replaced by the same volume of fresh drug-free dissolution medium. The samples were filtered through a $0.45 \mu \mathrm{m}$ filter, diluted and analyzed at 254 $\mathrm{nm}$ by UV spectrophotometer (Specord 40, analytic Jena, Germany), 
the drug concentration was calculated from the calibration curve [15]. In addition, the dissolution test was conducted for the conventional cinnarizine tablet (Stugeron ${ }^{\circledR} 25 \mathrm{mg}$ tablet) as a reference using the same procedure and conditions as that for the prepared ODTs of cinnarizine.

\section{Drug content (assay)}

From each formula of the prepared cinnarizine ODTs, 10 tablets were randomly selected and powdered. An equivalent amount of 25 $\mathrm{mg}$ of cinnarizine was taken and dissolved in $0.1 \mathrm{~N} \mathrm{HCl}$, filtered and analyzed for drug content at $\lambda$ threax (254) by UV -visible spectrophotometer [17].

\section{Fourier transforms infrared (FTIR) studies}

Fourier transforms infrared (FTIR) spectra of cinnarizine alone, and mixtures of 1:0.57 of cinnarizine with Kyron, and 1:5.3 of cinnarizine with lactose (which represented the actual ratio of the constituent of the formula F9c), were recorded to detect any possible interaction between cinnarizine and other excipients. IR-spectrophotometer (Thermo Mattson IR 300, USA) was used with potassium bromide disc; the scanning range was $500-4000 \mathrm{~cm}^{-1}[18]$.

\section{Stability study}

The selected ODTs formula (formula F9c) was subjected to accelerated stability study for three months at $40{ }^{\circ} \mathrm{C}$ in a stability chamber (Newtronic, India) with $75 \% \pm 5$ relative humidity (RH). In addition stability at $25^{\circ} \mathrm{C}$ with $60 \pm 5$ relative humidity (RH) for three months was conducted where samples were withdrawn every month and evaluated [19].

\section{Statistical analysis}

The software Excel 2013 using t-test and ANOVA was used for statistical analysis, the difference was considered to be statistically significant when $\mathrm{P}<0.05$ and non-significant when $\mathrm{P}>0.05$. Mean, and standard deviation was used to express the values in the data.

\section{RESULTS AND DISCUSSION}

\section{Flowability study of the prepared powder mixtures}

The results of the flowability study showed that those formulae that were prepared using mannitol as a diluent (F1, F2, and F3) had excellent flow properties. The angle of repose was in the range of (24.98 \pm 0.36 to $28.319 \pm 1.52$ ), Carr's index was less than $10 \%$, and Hausner's ratio was less than 1.11. This was due to the free-flowing nature of the granulated form of mannitol (Perlitol 300 DC) [20].

The formulae that were prepared with MCC diluent (F4, F5, and F6) showed flow properties ranged from good to fair. The angle of repose was in the range of $(34.43 \pm 0.14$ to $40.44 \pm 3.70)$, Carr's index was in the range of $(10.69 \pm 0.887 \%$ to $16.39 \pm 0.27 \%)$, and Hausner's ratio was in the range of $(1.11 \pm 0.015$ to $1.195 \pm 0.005)$ because MCC is made up of crystalline powder that is porous in nature with a low bulk density which hinders its flowability [21]. The formulae (F7, F8, and F9) that were prepared with the diluent lactose (super Tab® 40LL) showed good to excellent flow properties, the angle of repose was in the range of (24.83 \pm 2.19 to $34.4 \pm 0.43)$, Carr's index was in the range of $(6.37 \pm 0.94 \%$ to $14.49 \pm 0.054 \%)$ and Hausner's ratio was in the range of $(1.065 \pm 0.007$ to $1.1694 \pm 0.021)$ due to the presence of lactitol monohydrate in its composition which enhanced its flow properties [22].

\section{Evaluation of cinnarizine orally disintegrating tablets}

The hardness of the tablets from all of the formulae was within an acceptable range $(21.97 \pm 1.76 \mathrm{~N}$ to $31.55 \pm 4.40 \mathrm{~N})$. The highest hardness value was observed for the formulae F4, F5, and F6 due to the strong inter-particle force between MCC particles [7]. In addition to the acceptable friability of less than $1 \%$. Tablets thickness was in the range of $(2.88 \pm 0.03 \mathrm{~mm}$ to $2.97 \pm 0.02 \mathrm{~mm})$, except for the formulae F4, F5, and F6, in which higher thickness range was reported $(3.46 \pm 0.02 \mathrm{~mm}$ to $3.59 \pm 0.07 \mathrm{~mm}$ ), due to the low bulk density of MCC that was used as a diluent for them [21]. The weight variation was acceptable and within the pharmacopoeial limits, and the drug content was found to be good and not less than $90 \%$ or more than $110 \%$ which is the required limit [3].

\section{Disintegration time}

The disintegration time was in the range of $(4.33 \pm 1.53 \mathrm{~s}$ to $28.02 \pm 7.1 \mathrm{~s}$ ) as shown in table 2. The formulae F5 and F6 that were prepared with the diluent MCC showed the shortest disintegration time which may be due to the self-disintegration property of MCC (it disintegrate by capillary and swelling mechanism) which was complimentary with the disintegration properties of the super disintegrants that were used [23]. Lactose showed shorter disintegration time than mannitol which may be attributed to the reported spontaneous disintegration property of lactose [24].

Coming to the effect of the super disintegrant on disintegration time, $\mathrm{CP}$ revealed the shortest disintegration time among the other super disintegrants in the formulae that were prepared with mannitol (F1, F2, and F3), (ANOVA, ${ }^{*} \mathrm{P}<0.05$ ) and lactose (F7, F8, and F9), (ANOVA, $\left.{ }^{*} \mathrm{P}<0.01\right)$. The order of the disintegration time in such formulae was found to be CP>Kyron T-314>SSG. CP with its porous structure quickly absorbs water into the tablet by capillary action followed by secondary swelling which results in rapid disintegration of the tablet [25]. Kyron disintegrates evenly by wicking mechanism mainly, also by swelling on hydration [26]. SSG disintegrates by swelling, but unlike CP and Kyron T-314, it gels at a high level which may result in the formation of a thick viscous barrier that retards disintegration [27]. These results are in agreement with the results obtained by Swatantra et al. (2014), in a comparative study on the effect of various super disintegrants in the formulation of ibuprofen fast dissolving tablets [28].

Conversely, the formulae that were prepared with the diluent MCC; $\mathrm{CP}$ revealed the longest disintegration time in the formula $\mathrm{F} 4$ compared with that of F5 and F6. It may be due to the lower water absorption ratio of the formula $\mathrm{F} 4$ with this super disintegrant when compared with that of SSG and Kyron T-314 (F5 and F6) as shown in table 2 .

\section{Wetting time}

Wetting time can be regarded as one of the vital parameters to predict how much of the fluid is enough for breaking the tablet when placed upon the tongue (fig. 1). All of the tested formulae were wetted within an acceptable time of less than one minute as illustrated in table 2, which indicated their ability to absorb water and swell. The results were in the range of $2.72 \pm 0.75 \mathrm{~s}$ to $43.64 \pm 6.4 \mathrm{~s}$. The shortest wetting time was with the formulae that were prepared with MCC (F4, F5, and F6 with the wetting time of $10.03 \pm 3.01 \mathrm{~s}$, $4.62 \pm 0.68 \mathrm{~s}$, and $2.72 \pm 0.75 \mathrm{~s}$ respectively), this could be due to its porous structure [21].

The type of the super disintegrant had a significant effect on wetting time in the formulae F4, F5, and F6 that were prepared with the diluent MCC. Like the disintegration time, the formula F4 that was prepared with the super disintegrant $\mathrm{CP}$ showed the longest wetting time $(10.03 \pm 3.01 \mathrm{~s})$ compared with those prepared with SSG and Kyron-T314 (4.62 $\pm 0.68 \mathrm{~s}$ and $2.72 \pm 0.75 \mathrm{~s})$ respectively (ANOVA, $* \mathrm{P}<0.05$ )

\section{Water absorption ratio}

The highest water absorption ratio was observed for the formulae that were prepared with MCC, followed by those prepared with lactose then mannitol, as illustrated in table 2 . The effect of the super disintegrant on water absorption ratio appeared when MCC was used as a diluent. The super disintegrant SSG significantly increased the water absorption ratio from $115.27 \pm 5.68 \%$ and $182.49 \pm 13.75 \%$ when $\mathrm{CP}$ and Kyron T-314 were used as super disintegrants to $232.39 \pm 8.62 \%$ which may lead to less patient compliance due to the long stay on the tongue (ANOVA, ${ }^{* *} \mathrm{P}<0.01$ ). These results are in agreement with the results obtained by Lakshmi et al. (2013) who made a comparative evaluation of natural and synthetic superdisintegrants in the formulation of fast dissolving tablets [29]. Moreover, when the concentration of Kyron T-314 increased from $5 \%$ in the formula $\mathrm{F} 9$ to $8 \%$ in formula F9c, the water absorption ratio increased from $58.52 \pm 0.51 \%$ to $81.45 \pm 7.04 \%$ (ANOVA, ${ }^{*} \mathrm{P}<0.05$ ), while the disintegration and wetting time were not significantly affected. 


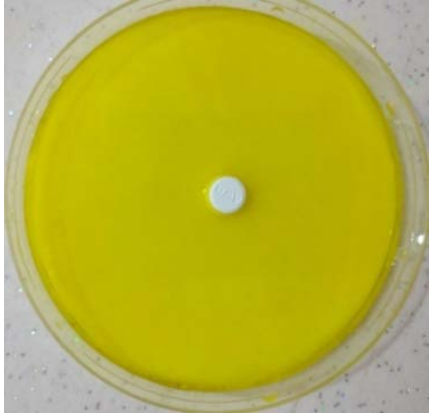

(A)

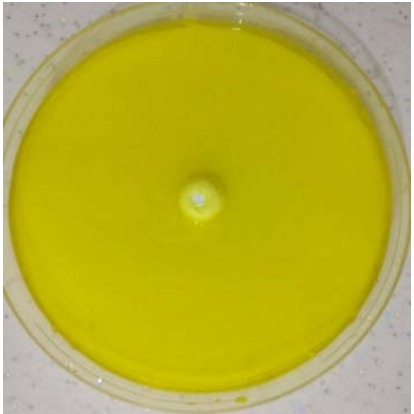

(B)

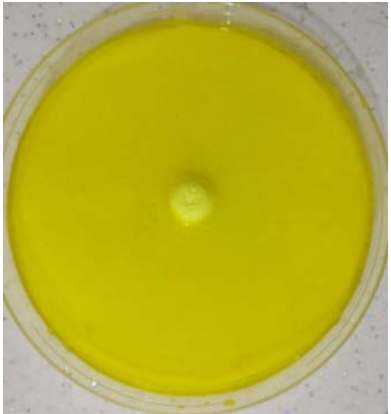

(C)

Fig. 1: The morphological changes of the prepared ODTs of cinnarizine (formula F9c) during wetting time test, (A) at time zero, (B) during wetting, (C) after complete wetting (17.75s). $n=3$

\section{Dissolution test}

The ODTs of cinnarizine were subjected to the dissolution test using $0.1 \mathrm{~N} \mathrm{HCl}(\mathrm{pH}=1.2)$ as a dissolution medium. The release data obtained through the dissolution study is shown in table 2 . The release profiles in fig. 2, fig. 3 , and fig. 4 demonstrated that among the different types of diluents, lactose revealed the highest percentage of the drug released that reached up to $61.46 \pm 4.60 \%$ in the formula F9 after 2 min. The reason may be related to the high water solubility of the type of lactose that was used in this work (SuperTab ${ }^{\circledR} 40 \mathrm{LL}$ ) when compared with the others. It was composed of anhydrous lactose and lactitol monohydrate, the dissolution rate of anhydrous $\beta$-lactose is 10 times more than that of $\alpha$-lactose monohydrate [30], while MCC is practically insoluble in water [31].

In fact, the type of the super disintegrants had no significant effect on the percentage of the drug released in the formulae that were prepared with the diluent mannitol (F1, F2, and F3) (fig. 5). While the super disintegrant Kyron T-314 significantly increased the percentage of the drug released in the formula F6 that was prepared with the diluent MCC, $(51.24 \pm 8.34 \%$ after $2 \mathrm{~min})$ when compared with the other formulae with this type of diluent (F4 and F5), (fig. 6), (ANOVA, ${ }^{* *} \mathrm{P}<0.01$ ). Similarly, in the formulae that were prepared with the diluent lactose, the super disintegrant Kyron T-314 revealed the highest percentage of the drug released $(61.46 \pm 4.60 \%$ after $2 \mathrm{~min}$ in the formula F9) among the formulae that were prepared with lactose (ANOVA, ${ }^{* *} \mathrm{P}<0.01$ ) and all other formulae (F1-F9), (fig. 7). Kyron T-314 increased the porosity of cinnarizine tablets due to which the absorption of water takes place at a higher rate that results in breaking of the tablets and therefore faster disintegration/dissolution [32]. These results are in agreement with the results obtained by Gattu and Lakshmi (2011), who made a comparative evaluation of natural and synthetic super-disintegrants with newer superdisintegrant Kyron T-314 [33].
By increasing the percentage of Kyron-T314 from 5\% in the formula, F9 to $8 \%$ in the formula F9c the percentage of the drug release dafter 2 min increased from $61.46 \pm 4.60$ to $74.55 \pm 3.0$ (fig. 8), (ANOVA, $\left.{ }^{* *} \mathrm{P}<0.01\right)$. These results were much higher than that of the commercially available cinnarizine tablets (Stugeron ${ }^{\circledR} 25 \mathrm{mg}$ tablet), in which only $8.75 \pm 2.15 \%$ of the drug was released within $2 \mathrm{~min}$.

Results of the release kinetic models showed that all of the formulae followed the first order kinetics. The $\mathrm{k}_{1}$ value increased in all of the formulae with increasing of the percentage of the drug released (table 2). From the above results, formula F9c can be selected as the most appropriate formula that showed rapid disintegration $(11.66 \pm 2.25 \mathrm{~s})$ when compared with that of the marketed one $(312 \pm 4.32 \mathrm{~s})$, (t-test, ${ }^{* *} \mathrm{P}<0.01$ ), with the highest dissolution profile among the other formulae.

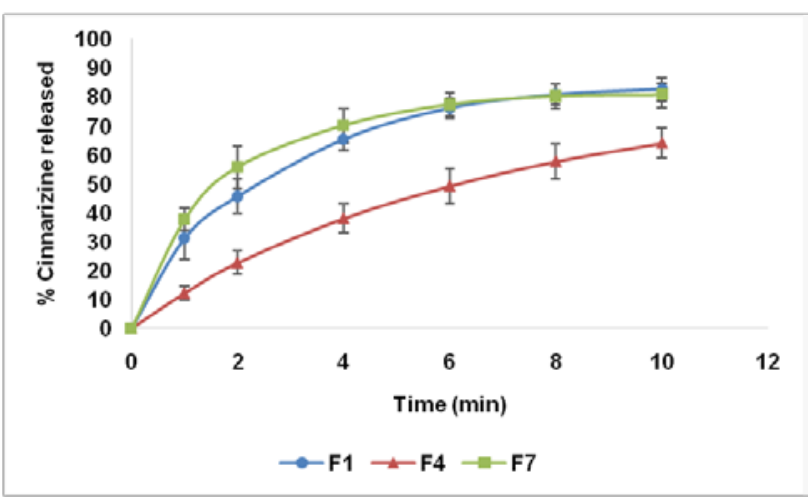

Fig. 2: Percentage release of cinnarizine from the prepared ODTs with different types of diluents in the presence of the super disintegrant (crospovidone). $n=6$; Data are expressed as mean $\pm S D$

Table 2: Evaluation of cinnarizine ODTs

\begin{tabular}{|c|c|c|c|c|c|c|}
\hline $\begin{array}{l}\text { Formula } \\
\text { type }\end{array}$ & $\begin{array}{l}\text { Disintegration } \\
\text { time* }^{*}(s)\end{array}$ & $\begin{array}{l}\text { Wetting } \\
\text { time }^{* *}(s)\end{array}$ & $\begin{array}{l}\text { Water Abs -orption ratio } \\
\text { after } 10 \mathrm{~s}^{* *}(\%)\end{array}$ & $\begin{array}{l}\text { Drug content** } \\
(\%)\end{array}$ & $\begin{array}{l}\text { Drug released after } \\
2 \mathrm{~min}(\%)\end{array}$ & $K_{1}\left(\min ^{-1}\right)$ \\
\hline F1 & $8.33 \pm 0.57$ & $21.23 \pm 7.1$ & $31.81 \pm 2.04$ & $92.43 \pm 0.38$ & $45.63 \pm 5.86$ & 0.3047 \\
\hline $\mathrm{F} 2$ & $28.02 \pm 7.1$ & $43.64 \pm 6.41$ & $15.95 \pm 0.169$ & $90.42 \pm 0.30$ & $40.07 \pm 5.25$ & 0.2560 \\
\hline F3 & $16.10 \pm 3.60$ & $34.67 \pm 7.70$ & $20.74 \pm 1.41$ & $90.03 \pm 0.03$ & $45.77 \pm 5.86$ & 0.3060 \\
\hline $\mathrm{F} 4$ & $12.33 \pm 1.53$ & $10.03 \pm 3.01$ & $115.27 \pm 5.68$ & $90.06 \pm 0.02$ & $22.69 \pm 4.01$ & 0.1286 \\
\hline F5 & $5.66 \pm 0.57$ & $4.62 \pm 0.68$ & $232.39 \pm 8.62$ & $94.42 \pm 0.48$ & $29.89 \pm 8.67$ & 0.1775 \\
\hline F6 & $4.33 \pm 1.53$ & $2.72 \pm 0.75$ & $182.49 \pm 13.75$ & $93.13 \pm 1.10$ & $51.24 \pm 8.34$ & 0.3592 \\
\hline F7 & $6.66 \pm 0.57$ & $14.72 \pm 3.61$ & $58.51 \pm 6.78$ & $90.01 \pm 0.34$ & $55.76 \pm 7.41$ & 0.4078 \\
\hline F8 & $15 \pm 2.65$ & $22.24 \pm 5.71$ & $49.97 \pm 3.39$ & $92.38 \pm 0.08$ & $45.83 \pm 7.82$ & 0.3065 \\
\hline F9 & $9.33 \pm 2.06$ & $15.05 \pm 4.25$ & $58.52 \pm 0.51$ & $93.28 \pm 0.05$ & $61.46 \pm 4.60$ & 0.4768 \\
\hline F9a & $9.66 \pm 2.25$ & $15.53 \pm 3.59$ & $62.81 \pm 5.05$ & $91.93 \pm 2.05$ & $62.96 \pm 5.81$ & 0.4966 \\
\hline F9b & $11 \pm 2$ & $17.74 \pm 1.38$ & $78.76 \pm 6.61$ & $95.3 \pm 6.12$ & $71.04 \pm 4.07$ & 0.6197 \\
\hline F9c & $11.66 \pm 2.25$ & $17.75 \pm 1.67$ & $81.45 \pm 7.04$ & $93.15 \pm 0.51$ & $74.55 \pm 3.01$ & 0.6843 \\
\hline $\begin{array}{l}\text { Stugeron } ® 25 \mathrm{mg} \\
\text { tablet }\end{array}$ & $312 \pm 4.32$ & - & - & $92.29 \pm 1.40$ & $8.75 \pm 2.15$ & - \\
\hline
\end{tabular}

$\mathrm{K}_{1}$ : First order release constant, ${ }^{*}$ Average of six reading $\pm \mathrm{SD}$, ${ }^{* *}$ Average of three reading $\pm \mathrm{SD}$ 


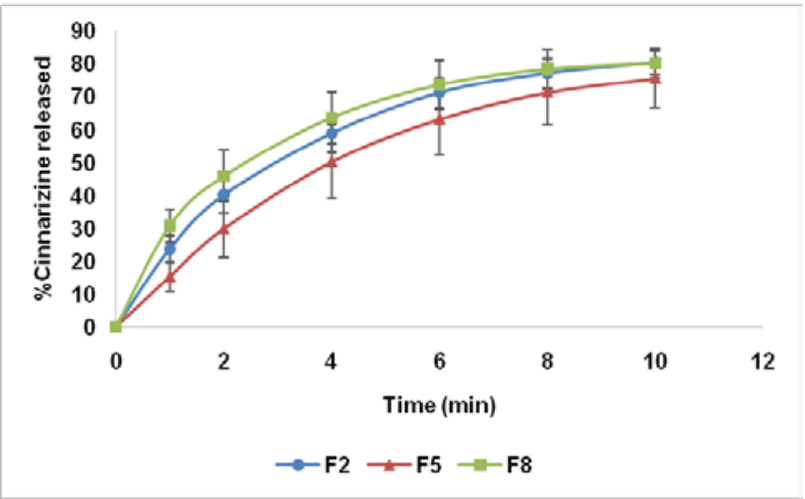

Fig. 3: Percentage release of cinnarizine from the prepared ODTs with different types of diluents in the presence of the super disintegrant $S S G$. $n=6$; data are expressed mean \pm SD

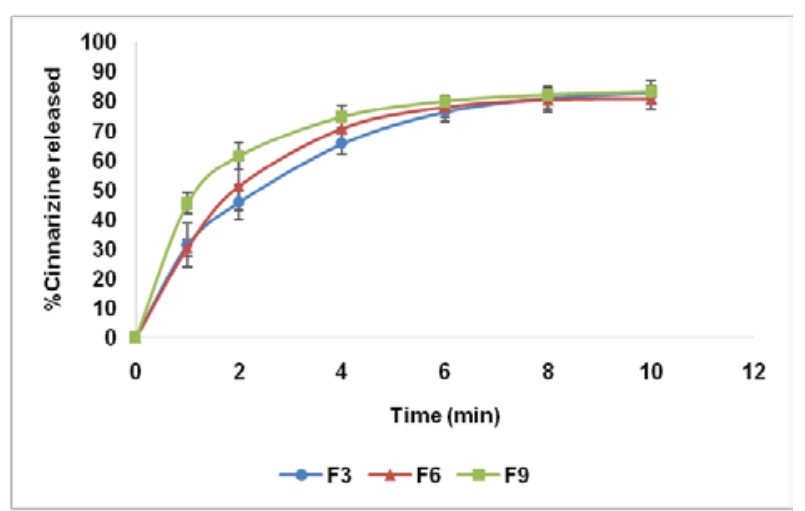

Fig. 4: Percentage release of cinnarizine from the prepared ODTs with different types of diluents in the presence of the super disintegrant Kyron T-314. $n=6$; Data are expressed as mean \pm SD

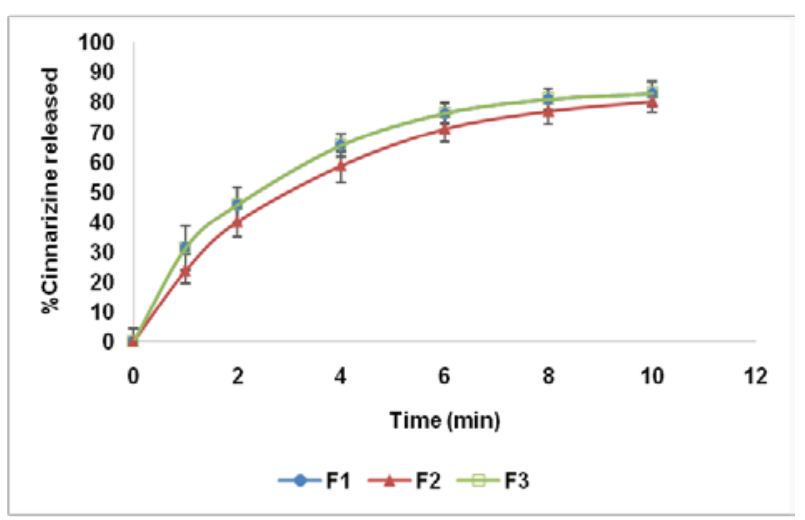

Fig. 5: Percentage release of cinnarizine from ODTs prepared with different types of super disintegrants and mannitol diluent. $n=6$; Data are expressed as mean $\pm S D$

\section{Fourier transforms infrared (FTIR) studies}

The FTIR studies showed no detected chemical interaction between cinnarizine, Kyron T-314, and lactose. Fig. 9 shows that there were no noticed shift in peaks or extra peaks appeared when comparing
IR of cinnarizine alone (fig. 9, a), lactose alone (fig. 9, b), Kyron T314 alone (fig. 9, c) with the IR chart of the physical mixture of cinnarizine and lactose (fig. 9, d), cinnarizine and Kyron T-314 (fig. 9, e).

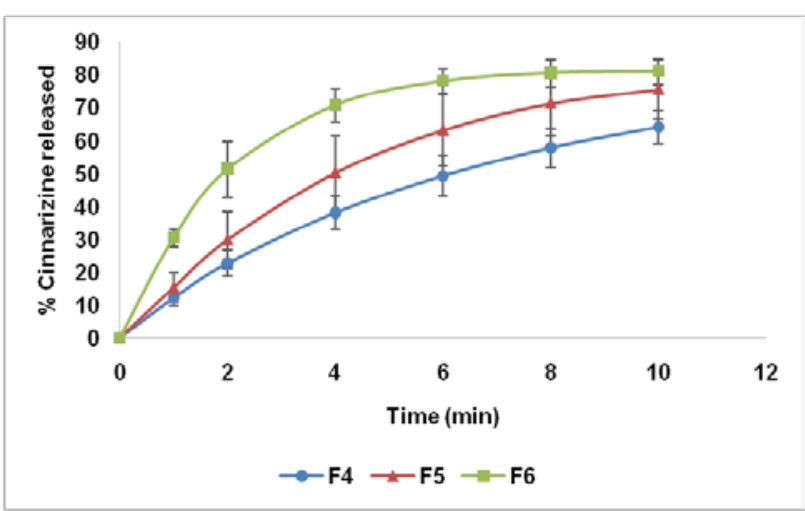

Fig. 6: Percentage release of cinnarizine from ODTs prepared with different types of super disintegrants and MCC diluent. $n=6$; Data are expressed as mean $\pm S D$

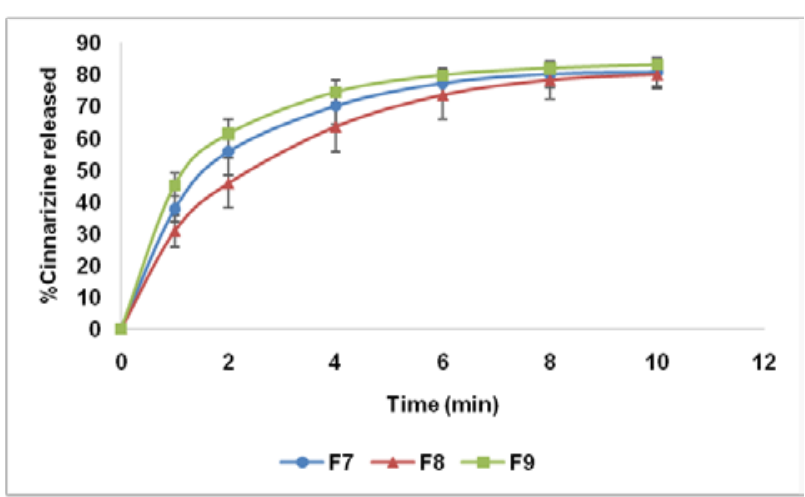

Fig. 7: Percentage release of cinnarizine from ODTs prepared with different types of super disintegrants and lactose diluent. $\mathrm{n}=6$; Data are expressed as mean $\pm S D$

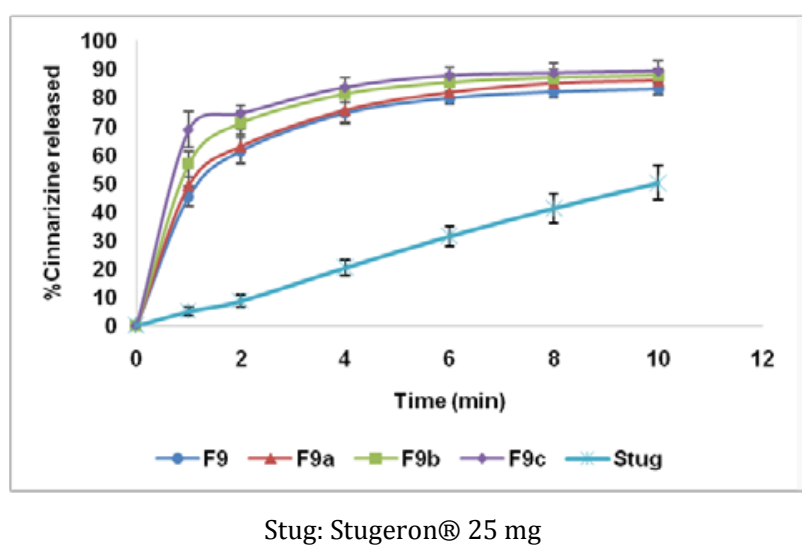

Fig. 8: Percentage release of cinnarizine from ODTs (F9, F9a F9b, F9c), prepared with a different concentration of the super disintegrant (Kyron T-314), and from the marketed product, Stugeron ${ }^{2} 25$ mg. n=6; Data are expressed as mean \pm SD 


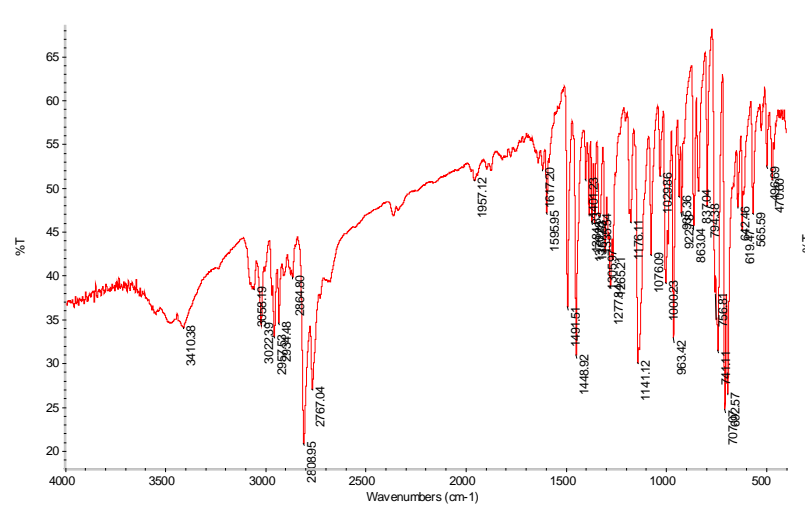

(a)

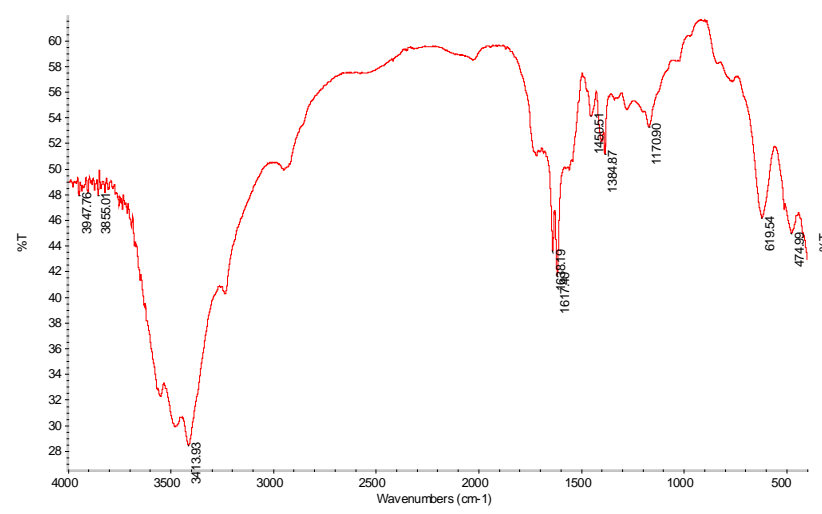

(c)

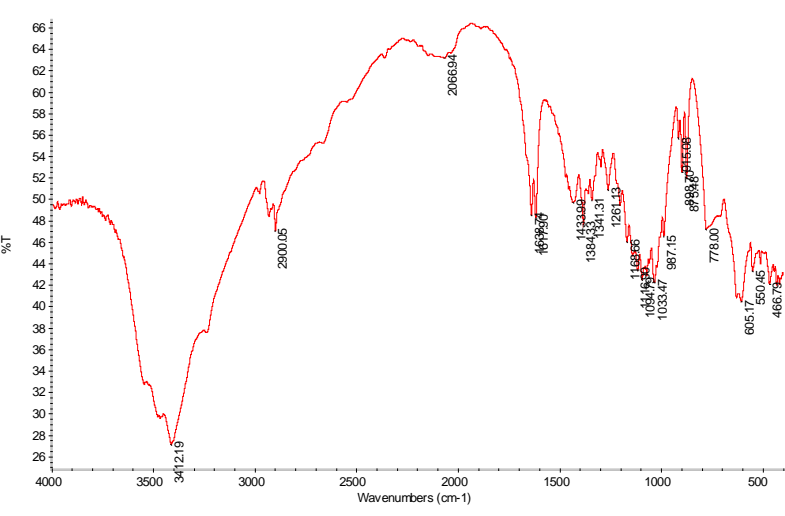

(b)

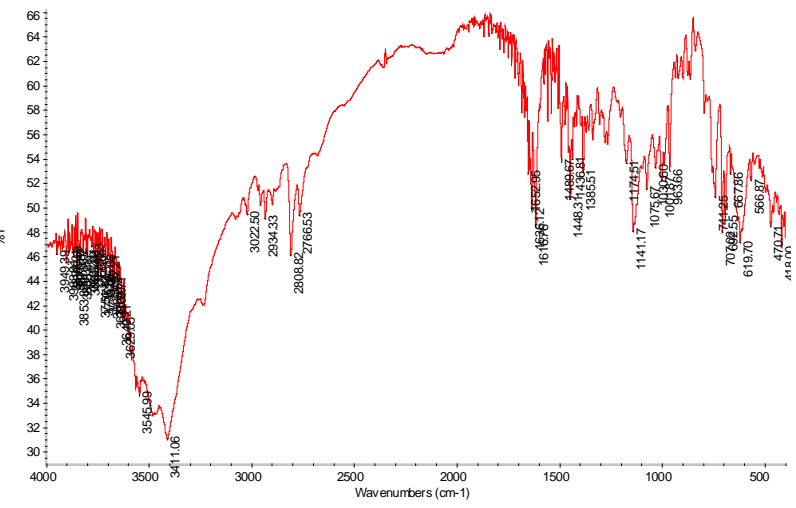

(d)

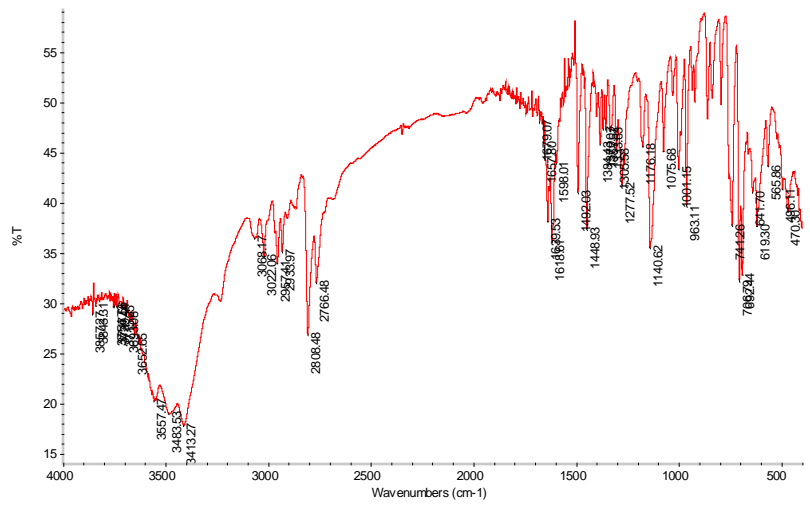

(e)

Fig. 9: FTIR spectra of cinnarizine alone (a), lactose alone (b), Kyron T-314 alone (c), cinnarizine and lactose (d), cinnarizine and Kyron T-314 (e)

\section{Stability study}

The results of the stability study of the optimized formula (F9c) showed that there were no significant changes in hardness, friability, disintegration, drug release and drug content of the examined tablets through the stability study (table 3). The only exception is the noticed increase in weight that was observed for the tablets stored at $40{ }^{\circ} \mathrm{C}, 75 \% \pm 5 \mathrm{RH}$ which might be due to the hygroscopic nature of the anhydrous lactose that presents in the tested formula [34].

Table 3: Stability study data of ODTs of cinnarizine

\begin{tabular}{llll}
\hline Days & Stability conditions & Drug content** $^{* *}$ ) & Disintegration time* $^{*}$ (s) \\
\hline At time zero & - & $93.15 \pm 0.51$ & $11.66 \pm 2.25$ \\
30 & $25 \mathrm{C}^{\circ}$ and $60 \pm 5 \mathrm{RH}$ & $93.23 \pm 0.06$ & $11.03 \pm 1.34$ \\
& $40 \mathrm{C}^{\circ}$ and $75 \pm 5 \mathrm{RH}$ & $94.22 \pm 0.70$ & $11.39 \pm 2.25$ \\
60 & $25 \mathrm{C}^{\circ}$ and $60 \pm 5 \mathrm{RH}$ & $96.8 \pm 0.92$ & $10.60 \pm 2.26$ \\
& $40 \mathrm{C}^{\circ}$ and $75 \pm 5 \mathrm{RH}$ & $96.01 \pm 1.23$ & $10.86 \pm 2.321$ \\
90 & $25 \mathrm{C}^{\circ}$ and $60 \pm 5 \mathrm{RH}$ & $93.76 \pm 1.56$ & $11.16 \pm 0.75$ \\
& $40 \mathrm{C}^{\circ}$ and $75 \pm 5 \mathrm{RH}$ & $93.59 \pm 0.268$ & $10.83 \pm 1.16$ \\
\hline
\end{tabular}

${ }^{*}$ Average of six reading $\pm \mathrm{SD},{ }^{* *}$ Average of three reading $\pm \mathrm{SD}$ 


\section{CONCLUSION}

Owing to that cinnarizine is a class II drug according to the biopharmaceutical classification system (BCS), so any improvement in the dissolution will lead to enhancement of the bioavailability. It was successfully formulated as ODTs by using direct compression method. Among the various diluents used, lactose was selected. In addition, different super disintegrants were used, the super disintegrant Kyron T-314 was the most successful one when used with the diluent lactose. It played an important role in decreasing the disintegration time and enhancing the dissolution of the drug. The selected formula showed acceptable characteristics, rapid disintegration and dissolution, and good stability. Accordingly, the selected formula (F9c) represents a promising formula for preparing ODTs by using the simple, direct compression strategy.

\section{ACKNOWLEDGMENT}

We are very grateful to Hawler Medical University, College of Pharmacy, and to Awamedica Company for the pharmaceutical industry (Erbil, Iraq) for providing the essential facility to accomplish this work.

\section{AUTHORS CONTRIBUTIONS}

All the authors have contributed equally

\section{CONFLICTS OF INTERESTS}

Declared none

\section{REFERENCES}

1. Gryczke A, Schminke S, Maniruzzaman M, Beck J, Douroumis D. Development and evaluation of orally disintegrating tablets (ODTs) containing Ibuprofen granules prepared by hot melt extrusion. Colloids Surf B 2011;86:275-84.

2. Abdelbary G, Prinderre P, Eouani C, Joachim J, Reynier JP, Piccerelle P. The preparation of orally disintegrating tablets using a hydrophilic waxy binder. Int J Pharm 2004;278:423-33.

3. Ph. Eur. European Pharmacopoeia. 9th ed. Council of Europe, Strasbourg; 2017.

4. Prajapati BG, Patel SN. Formulation, evaluation, and optimization of the orally disintegrating tablet of cinnarizine. E-J Sci Technol 2010;1:9-21.

5. Bhowmik D, Chiranjib B, Chandira RM. Fast dissolving tablet: an overview. J Chem Pharm Res 2009;1:163-77.

6. Singh S, Shah D. Development and characterization of mouth dissolving tablet of zolmitriptan. Asian Pacific J Trop Dis 2012;2(Suppl 1):S457-64.

7. Abdelbary A, Elshafeey AH, Zidan G. Comparative effects of different cellulosic-based directly compressed orodispersable tablets on the oral bioavailability of famotidine. Carbohydr Polym 2009;77:799-806.

8. Tripathi K. Essentials of medical pharmacology; 2013. Available from: http://www.jaypeedigital.com/book details. aspx?id=9789350259375andsr $=1$. [Last accessed on 05 Aug 2018].

9. Martindale W. Martindale the extra pharmacopoeia hardcover. 31st ed. Rittenhouse Book Distributors; 1996.

10. Bergström CAS, Fagerberg J, Tsinman O, Tsinman K, Avdeef A. Dissolution rate and apparent solubility of poorly soluble compounds in biorelevant fluids. Mol Pharm 2010;5:1801.

11. USP 33-NF 28. United States Pharmacopeial Convention. Rockville MD, USA; 2010.

12. Traina K, Cloots R, Bontempi S, Lumay G, Vandewalle N, Boschini F. Flow abilities of powders and granular materials evidenced from dynamical tap density measurement. Powder Technol 2013;235:842-52.

13. Shivakumar HN, Kumar MR. Formulation of fast dissolving tablets of doxazocin mesylate drug by direct compression method. Int J Appl Pharm 2017;9:22-8.
14. Nagar P, Singh K, Chauhan I, Verma M, Yasir M, Khan A, et al. Orally disintegrating tablets: formulation, preparation techniques, and evaluation. J Appl Pharm Sci 2011;1:35-45.

15. Patel BP, Patel JK, Rajput GC, Thakor RS. Formulation and evaluation of mouth dissolving tablets of cinnarizine. Indian J Pharm Sci 2010;72:522-5.

16. Santosh Kumar R, Naga Satya Yagnesh T, Goutham Kumar Gitam V. Optimisation of ibuprofen fast dissolving tablets employing starch xanthate using 23 factorial design. Int J Appl Pharm 2017;9:51-9.

17. Tambawala TS, Shah PJ, Shah SA. Orally disintegrating tablets of cinnarizine and domperidone: a new arsenal for the management of motion sickness. J Pharm Sci Tech Mgmt 2015;1:81-97.

18. Shaikh RH, Jamadar MJ, Patil AD, Tamboli SM. Formulation and in vitro evaluation of antiemetic orodispersible combination tablets of domperidone and cinnarizine by using various superdisintegrants. Pharmatutor 2015;3:49-59.

19. Bajaj S, Singla D, Sakhuja N. Stability testing of pharmaceutical products. J Appl Pharm Sci 2012;2:129-38.

20. Rowe RC. editor. Handbook of pharmaceutical excipients. 6. ed. London: APhA, (PhP) Pharmaceutical Press; 2009.

21. Thoorens G, Krier F, Leclercq B, Carlin B, Evrard B. Microcrystalline cellulose, a direct compression binder in quality by design environment-a review. Int $\mathrm{J}$ Pharm 2014;473:64-72.

22. Jivraj M, Martini LG, Thomson CM, Thomson CM. An overview of the different excipients useful for the direct compression of tablets. PSTT 2000;3:58-63.

23. Yassin S, Goodwin DJ, Anderson A, Sibik J, Wilson DI, Gladden $\mathrm{LF}$, et al. The disintegration process in microcrystalline cellulose-based tablets, part 1: influence of temperature, porosity, and superdisintegrants. J Pharm Sci 2015;104:344050.

24. Ferrari F, Bertoni M, Bonferoni MC, Rossi S, Caramella C, Nyström C. Investigation on bonding and disintegration properties of pharmaceutical materials. Int J Pharm 1996;136:71-9.

25. Battu SK, Repka MA, Majumdar S, Madhusudan RY. Formulation and evaluation of rapidly disintegrating fenoverine tablets: effect of superdisintegrants. Drug Dev Ind Pharm 2007;33:1225-32.

26. Bele MH, Derle DV. Mechanism of disintegrant action of polacrilin potassium: swelling or wicking? Acta Pharm Sin B 2012;2:70-6

27. Setty CM, Prasad DVK, Gupta VRM, Sa B. Development of fast dispersible aceclofenac tablets: effect of the functionality of superdisintegrants. Indian J Pharm Sci 2008;70:180-5.

28. Swatantra S, Shweta S, Anil S. Comparative study on the effect of various superdisintegrants in the formulation of ibuprofen fast dissolving tablets. Int J Pharma Res Rev 2014;3:26-33.

29. Lakshmi PK, Narendra Y, Rewanthwar SL, Neeharika V. Comperative evaluation of natural and synthetic superdisintegrants in the formulation of fast dissolving tablets. Turk J Pharm Sci 2013;10:351-66.

30. Gohel MC. A review of co-processed directly compressible excipient. J Pharm Pharm Sci 2005;8:76-93.

31. BP. British Pharmacopoeia. London, Stationary office; 2017.

32. Abd-El Bary A, Louis D, Sayed S. Olmesartan medoxomil surface solid dispersion-based orodispersible tablets: formulation and in vitro characterization. J Drug Delivery Sci Technol 2014;24:665-72.

33. Gattu J, Lakshmi P. Comparative evaluation of natural and synthetic superdisintegrants with newer superdisintegrant kyron T-314. Acta Pharm Sci 2011;53:35-44.

34. Listiohadi Y, Hourigan JA, Sleigh RW, Steele RJ. Moisture sorption, compressibility and caking of lactose polymorphs. Int J Pharm 2008;359:123-34. 